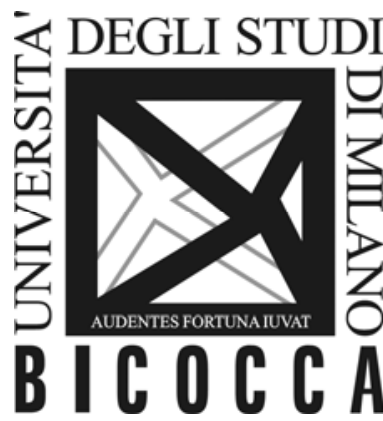

DEPARTMENT OF ECONOMICS

UNIVERSITY OF MILAN - BICOCCA

WORKING PAPER SERIES

To Give or Not To Give? Equity, Efficiency and Altruistic Behavior in a Survey-Based Experiment

\author{
Vittorio Pelligra, Luca Stanca \\ No. 202 - December 2010
}

Dipartimento di Economia Politica

Università degli Studi di Milano - Bicocca

http://dipeco.economia.unimib.it 


\title{
To Give or Not To Give? Equity, Efficiency and Altruistic Behavior in a Survey-Based Experiment
}

\author{
Vittorio Pelligra* and Luca Stanca ${ }^{\dagger}$
}

December 2010

\begin{abstract}
This paper presents the results of a survey-based experiment on the role of equity and efficiency for altruistic behavior. Using simple binary decisions for a representative pool of subjects, we find that both equity and efficiency are relevant for the decision to give. However, contrary to the findings in several laboratory experiments, our results indicate that equity plays a major role for altruistic behavior. Differences in relative payoffs have a significant effect on the decision to give. When giving is not costly, more than half of the subjects prefer equal payoffs to a socially efficient but unequal allocation. When giving is Pareto-improving, half the subjects choose to sacrifice a higher payoff in order to avoid payoff inequality. We also find that preferences, as revealed by experimental choices, are largely consistent with reported pro-social activities, while only weakly related to self-reported well-being.
\end{abstract}

Keywords: Altruism, Inequality-Aversion, Social Welfare, Envy, LargeScale Experiment.

JEL codes: D63, C78, C91.

*Economics Department, University of Cagliari \& CRENoS, V.le S.Ignazio 17, 09123 Cagliari, Italy. E-mail: pelligra@unica.it

${ }^{\dagger}$ Corresponding author. Economics Department, University of Milan Bicocca. Piazza dell'Ateneo Nuovo 1, 20126 Milan, Italy. E-mail: luca.stanca@unimib.it 


\section{Introduction}

Giving is an essential part of human interpersonal behavior that is still difficult to account for in the framework of standard economic models. Seasonal gift-giving, blood-donation, voluntary work, voluntary provision to public goods, financial contributions to charities, scientific activities and nongovernmental organizations, are all examples of other-regarding behavior in economically relevant areas. ${ }^{1}$ However, they are at odds with the assumption of purely self-interested behavior commonly made in economic theory.

In order to account for the growing body of field and laboratory experimental evidence that emphasizes the pervasiveness of other-regarding behavior, economists have recently introduced models of social preferences, in which different forms of non-selfish motivations play an important role for individual choices (e.g. Rabin, 1993, Fehr and Schmidt, 1999, Bolton and Ockenfels, 2000, Falk and Fischbacher, 2006). Equity, efficiency and reciprocity have been identified as the main drivers of pro-social behavior. These components of social preferences interact in a complex way and it may be difficult to assess their relevance for actual behavior in different situations.

In this paper, we present the results of a survey-based experiment aimed at investigating the respective roles of equity and efficiency for altruistic behavior. In order to eliminate the influences of direct and indirect reciprocity, and disentangle the effects of efficiency and distributional motives, we compare a series of binary-choice dictator games. One subject has to choose between two alternative monetary allocations for himself and another subject, with one of the two allocations implying a monetary gift for the other subject. The other subject has no active role, so that expectations about her behavior cannot elicit strategic considerations for the dictator. By exogenously varying the cost of giving and the distribution of the endowments, we are able to disentangle the effects of equity and efficiency on the decision to give.

Our study contributes to the literature in several ways. First, we implement a survey-based experiment that relies on a representative pool of subjects, rather than a small group of students as it is generally the case in laboratory economic experiments. Second, we use a within-subjects design where subjects play different versions of the baseline game in only one role. Avoiding role-switching is important to rule out the possibility that subjects may be influenced by some form of indirect or generalized reciprocity even in a dictator-game. Third, we examine the consistency between social pref-

\footnotetext{
${ }^{1}$ In 2009 in the United States charitable giving totalled $\$ 303.75$ billion. Annual individual giving generally exceeds $2 \%$ of GDP, with $90 \%$ of people giving money to at least one charity (Giving USA 2010; see also Andreoni, 2006).
} 
erences, as revealed by the experimental choices, and pro-social behavior, such as donations to charities and voluntary activities, as reported in a postexperimental questionnaire. Fourth, we investigate the relationship between revealed social preferences and self-reported well-being.

Our results based on a representative pool of subjects indicate that, contrary to several existing experimental studies conducted with students in the lab (Charness and Rabin, 2000, Charness and Grosskopf, 2001, Engelmann and Strobel, 2004), while both equity and efficiency are relevant for the decision to give relative payoffs play a major role. In particular, when giving is not costly, the majority of the subjects prefer equal payoffs to social efficiency. In addition, when giving is payoff-increasing, about half the subjects choose to decrease inequality through Pareto-damaging behavior. We also find that preferences, as revealed by experimental choices, are largely consistent with reported pro-social activities: a concern for efficiency in the experimental task is positively related to the probability of participating in voluntary activities. Inequity aversion negatively affects the probability of both making donations to charities and participating in voluntary activities. We do not find any significant relation between subjects' preferences and life satisfaction, whereas financial satisfaction is negatively affected by positional preferences: subjects who are willing to accept to be worse off in absolute terms in order to avoid being worse off in relative terms are ceteris paribus less satisfied with their objective conditions.

The paper is structured as follows. Section 2 briefly reviews the related literature. Section 3 describes the experimental design, hypotheses and procedures. Section 4 presents the results. Section 5 concludes.

\section{$2 \quad$ Related Literature}

Models that incorporate fairness in agents' preferences differ with respect to how fairness is defined (see e.g. Fehr and Gachter, 2000, Sobel, 2004, and Fehr and Schmidt, 2006, for recent surveys). In particular, two main classes of models can be distinguished: models that focus on distributional concerns, and models that focus on intention-detection.

In the distributional approach, fairness refers to the distribution of material payoffs. Agents are motivated not only by their own material gain, but also by how their payoff compares with that of other agents. Fehr and Schmidt (1999) assume that a subject's utility depends on the difference between her own payoff and that of other subjects, so that agents have egalitarian preferences. Bolton and Ockenfels (2000) assume that the utility function of a subject depends on her own payoff relative to the average overall payoff, 
so that agents care about their own relative status. In these models, fairnessrelated preferences depend only on the final distribution of payoffs, so that agents are not concerned about how a given distribution has been obtained.

The intention-based approach incorporates the role of other agents' perceived intentions in the form of "reciprocity" (Rabin, 1993, Dufwenberg and Kirchsteiger, 2004) or "fulfilling expectations" (Battigalli and Dufwenberg, 2007). Theories of reciprocity are built upon the idea of "reciprocating kindness", the willingness to repay a kind action and punish an unkind one, even at some cost. Theories of fulfilling expectations describe the tendency to fulfill others' expectations in order to avoid the feeling of guilt arising from letting others down.

The dichotomy between outcome- and intention-based models has been challenged by recent experimental results indicating that the two types of concerns, for equity and intentions, are not mutually exclusive and are generally acting simultaneously. ${ }^{2}$ Charness and Rabin (2002) and Falk and Fischbacher (2006) proposed mixed models in which both distribution and intentions play a role. In particular, in the theory of reciprocity by Falk and Fishbacher (2006) the kindness of an action depends on both intentionality and the perceived fairness of the outcome of an action, where the latter is defined as the difference in the payoffs of the receiving and sending subjects. In these models, actions with identical outcomes may elicit different reciprocal responses depending on how the underlying intentions are perceived and interpreted.

Charness and Rabin (2002) run a series of experimental games designed to test their model "more directly than the existing experiments" (p. 817). They found that, with respect to the distributional aspects of preferences, the social efficiency motive has more explanatory power that inequality-aversion. ${ }^{3}$ They conclude that "the role of inequality reduction has been exaggerated. Few subjects sacrifice money to reduce inequality by lowering another subject's payoff, and only a minority do so even when this is free [...] Unlike difference aversion, social welfare preferences can explain the finding in our data that about half of subjects make inequality-increasing sacrifices when these sacrifices are efficient and inexpensive" (p. 819-820). "Using simple binary decisions, Charness and Grosskopf, (2001) investigate the relevance of inequity aversion and its relationships with self-reported well-being. Their

\footnotetext{
${ }^{2}$ See Nelson, 2002; Falk, Fehr and Fischbacher, 2003, 2008; McCabe, Rigdon and Smith, 2003 and Sutter, 2007

3 "Subjects are more concerned with increasing social welfare and sacrificing to increase the payoffs for all recipients, especially low-payoff recipients, than with reducing differences in payoffs" (Charness and Rabin, 2002, p. 817).

${ }^{4}$ Charness and Grosskopf (2001) and Engelmann and Strobel (2004) find similar results.
} 
main conclusion is that "Most people appear to disregard relative payoffs, instead typically making choices resulting in higher social payoffs" (p. 301).

We consider a similar research question with some important departures in both the experimental design and underlying hypotheses. ${ }^{5}$ The main features of our study are the use of a large representative pool of subjects, instead of a relatively small sample of students, and the survey-based methodology. The key advantage of these features is the attenuation of the external validity problem. Most of the results in social preferences research come from lab experiments with self-selected students. Falk et al. (2010) calculate that 89 percent of papers published between 2004 and 2009 in five leading field journals are based on experiments with students. ${ }^{6}$ This may introduce systematic biases in the observations and, therefore, undermine the generalizability of the conclusion based on lab experiments. The use of a representative pool of subjects allows us to overcome such criticisms. In addition, the survey-based methodology allows us to compare self-reported data on giving and individual characteristics, with the observations on actual giving behavior in the dictator games.

Both the comparison between behavioral and stated preferences and the use of representative samples of subjects are at the heart of two distinct strands in the recent literature. The former aspect has been discussed first by Glaeser et al. (2000) in the context of a trust game. Their research question has been further investigated with a similar methodology by Fehr et al. (2003) and by Sapienza et al. (2007). Fehr et al. (2003) integrate behavioral and attitudinal measures but also consider, for the first time in this kind of analyses, a subset of 442 individuals from the German Socio-Economic Panel. Bellemare and Kroger (2007) and Bellemare et al. (2008) use a similar methodology. The former study combines choice data in the ultimatum game with other subjective variables from a subset of 501 individuals included in a large representative sample of the Dutch population. The latter study integrates the same design by considering expectations of proposers elicited by subjective probability questions. The use of a representative sample of subject is also the main feature of the experiment presented in Fong and Luttmer (2009). Their design considers a dictator game where the perceived characteristics of the recipients are artificially manipulated to investigate their effect on actual giving choices. ${ }^{7}$

\footnotetext{
${ }^{5}$ Since we are concerned mainly with the distributional motives we implemented only the dictator-games and not the "response-games".

${ }^{6}$ The journals are Games and Economic Behaviour, Journal of Public Economics, Economic Journal, Journal of Economic Behavior \& Organization, Experimental Economics.

${ }^{7}$ In designing the experiment we also considered the fact that, since giving increases with the level of education (Brown 2005; Havens et al., 2006; Rooney et al., 2005), the use
} 


\section{The Experiment}

\subsection{Design}

The baseline experimental task is a reduced dictator game. One subject (called $A$ ) has to choose between two alternative monetary allocations for himself and another subject (called $B$ ). Therefore, in each treatment, $A$ has to choose between $\left(\pi_{A}, \pi_{B}\right)$ and $\left(\pi_{A}^{\prime}, \pi_{B}^{\prime}\right)$, where $\pi_{A}$ and $\pi_{B}$ denote the payoffs of $A$ and $B$, respectively, measured in euros. Subject $B$ has a passive role. One of the two allocations, used as a benchmark, is always equal payoffs for the two subjects $(400,400)$. The alternative allocation is varied across four treatments, so that it entails a 100 euro difference for the payoff of $B$ relative to the benchmark. The choice between the two alternative allocations is thus between giving, or not giving, under different distributive and efficiency conditions. Figure 1 compares the payoffs in the four treatments, with the arrows representing the choice of giving against the alternative of not giving.

Treatments T1 and T2 examine the decision to give when giving is not costly for $A$, so that self-interest does not play any role. In $\mathrm{T} 1$, the alternative allocation is $(400,300)$, so that giving increases efficiency and decreases inequality. Equity and efficiency motives, if present, act in the same direction. The decision not to give may be motivated only by competitive preferences. In T2, the alternative allocation is $(400,500)$, so that giving increases efficiency while increasing inequality. Since equity and efficiency now act in opposite directions, this treatment allows us to assess which of the two components is dominant, in the absence of any impact if giving on one's own payoff. Treatments T3 and T4 examine the decision to give when giving is either costly (T3) or payoff-increasing (T4) for $A$. In T3, the alternative allocation is $(350,500)$ : giving is costly and increases efficiency while it increases inequality. In T4, the alternative allocation is $(450,500)$ : giving increases the payoff of both subjects while increasing inequality.

We also implement the four treatments T1-T4 using a larger gift size (400 euro). These treatments (T1L-T4L) are used to assess the effect of gift size within treatments and to check the consistency of choices across the four treatments.

of university students in experimental research on giving and donations tends to introduce a systematic bias that could lead to an overestimation of the phenomenon. This bias can be eliminated only by considering a representative sample of a population. 
Figure 1: Monetary allocations, by treatment (small gift size)

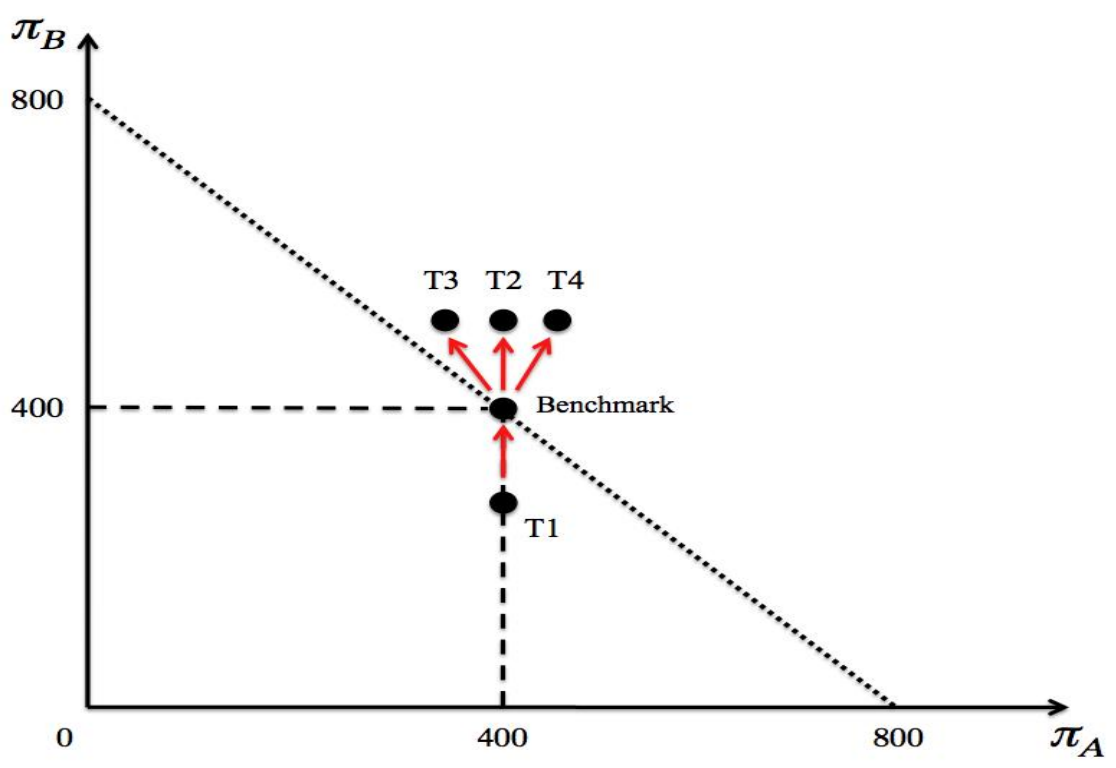

\section{$3.2 \quad$ Hypotheses}

Following Charness and Rabin (2002), we assume the following simplified description of player $A$ 's preferences:

$$
\begin{aligned}
& U_{A}\left(\pi_{A}, \pi_{B}\right)=\alpha \pi_{A}+\beta \pi_{B}-\theta\left(\pi_{A}-\pi_{B}\right) \text { if } \pi_{A}>\pi_{B} \\
& U_{A}\left(\pi_{A}, \pi_{B}\right)=\alpha \pi_{A}+\beta \pi_{B}-\delta\left(\pi_{B}-\pi_{A}\right) \text { if } \pi_{B}>\pi_{A}
\end{aligned}
$$

where $\pi_{A}$ and $\pi_{B}$ are the payoffs of players $A$ and $B$, respectively, and $\alpha, \beta, \delta, \theta \geq 0$. Assuming, for simplicity, that $\theta=\delta$ we obtain

$$
U_{A}\left(\pi_{A}, \pi_{B}\right)=\alpha \pi_{A}+\beta \pi_{B}-\delta\left|\pi_{B}-\pi_{A}\right|
$$

When deciding whether to give to another subject, an individual takes into account the change in its own payoff (self-interest, through $\alpha$ ), the change in the other subject's payoff (efficiency, through $\beta$ ), and the change in the difference between payoffs (inequality, through $\delta$ ). Note that, as in Engelmann and Strobel (2004), efficiency here is intended as the sum of payoffs, not as Pareto efficiency. ${ }^{8}$

\footnotetext{
${ }^{8}$ Note that the utility function can be rewritten as $U_{A}=(\alpha-\beta) \pi_{A}+\beta\left(\pi_{A}+\pi_{B}\right)$, so that $\beta$ measures the effect of changes in total payoff on $A$ 's utility.
} 
The first hypothesis we test is pure self-interest versus other-regarding preferences:

$$
H_{0}: \beta+\delta=0 \text { vs } H_{1}: \beta+\delta \neq 0
$$

In T1 (400,400 vs 400,300), if subjects are purely self-interested, they are indifferent between the two allocations. Alternatively, they might decide to give in order to increase $\pi_{B}$ and total payoff, or to decrease inequality. In Figure 1, since $M R S=\frac{\alpha-\delta}{\beta+\delta}$, under the null hypothesis indifference curves are vertical lines passing through the two alternative allocations. Defining $T_{i}$ as the proportion of those who decide to give in treatment $i$, under the null hypothesis $T_{1}=0.5$, whereas under the alternative $T_{1}>0.5$.

The second hypothesis we test is equity versus efficiency:

$$
H_{0}: \beta=\delta \text { vs } H_{1}: \beta \neq \delta
$$

In T2 (400,500 vs 400,400), by choosing to give, $A$ increases $\pi_{B}$ and total payoff, while also increasing inequality. The null hypothesis is that the effects of inefficiency aversion and inequality aversion balance each other versus the alternative that they are different. Since $M R S=\frac{\alpha-\delta}{\beta-\delta}$, under the null hypothesis indifference curves are vertical. The null hypothesis can be rejected if $T_{2} \neq 0.5$. Subjects who decide to give in T2 can be identified as Weak Altruist $(\beta>\delta)$, whereas those who decide not to give can be identified as Weak Positional $(\beta<\delta)$.

Note that the comparison between T1 and T2 allows us to assess the causal role played inequity aversion. As everything else is kept constant in the two treatments, any differences between $\mathrm{T} 2$ and $\mathrm{T} 1$ capture the effect of inequality on the decision to give

$$
H_{0}: \delta=0 \text { vs } H_{1}: \delta \neq 0
$$

In T3 (350,500 vs 400,400) we assess the specific role played by efficiency for the decision to give. Since giving is costly, if an agent is purely selfinterested, or motivated by inequity aversion, she would choose not to give. The comparison between T3 and T2 thus allows us to test the effect of the cost of giving. As everything else is kept constant in the two treatments, any differences between T3 and T2 capture the causal effect of the cost of giving on the decision to give.

In T4 $(450,500$ vs 400,500$)$ we assess the specific role played by inequity aversion for the decision to give. Since giving is payoff-increasing, if agents were purely self-interested, or driven by inefficiency aversion, they would choose to give. The comparison between T4 and T2 allows to test the effect of monetary rewards on giving. As everything else is kept constant in the 
two treatments, any differences between T4 and T2 capture the causal effect of an increase in own payoff on the decision to give.

Table 1 summarizes the alternative allocations in the four treatments with an indication of the corresponding theoretical predictions.

Table 1: Experimental design: treatments and predictions

\begin{tabular}{cccccc}
\hline \hline Treatment & GIVE & KEEP & Efficiency & Equality & Self interest \\
\hline T1 & 400,400 & 400,300 & + & + & $=$ \\
T2 & 400,500 & 400,400 & + & - & $=$ \\
T3 & 350,500 & 400,400 & + & - & - \\
T4 & 450,500 & 400,400 & + & - & + \\
\hline
\end{tabular}

Notes: Columns 4 to 6 report the expected sign of the corresponding motive on the decision to give. See Section 3.1 for a detailed description of the experimental design.

\subsection{Procedures}

We adopt a survey-based methodology that is attractive in several respects. First, it relies on a large and representative sample of the population. Second, it allows to provide substantial monetary incentives, as each subject was given the opportunity to gain up to 800 euros in relation to their responses in the choice task of the questionnaire. Third, it provides detailed information on both socioeconomic characteristics and pro-social activities carried out by subjects.

The experiment was conducted in December 2009 in Sardinia, an autonomous region of Italy, and involved a representative sample of 611 subjects, stratified by gender and place of residence. Subjects responded to a telephone interview in which, in addition to a series of questions on sociodemographic characteristics, beliefs, and pro-social activities, we included a choice task for the dictator games described in the previous section. The research was fielded by E-RES, a market research firm, and funded by IARES. ${ }^{9}$

Subjects were first contacted by telephone by the interviewers and asked to participate in a research on cultural values and social behaviors. Once they expressed their consent and answered a few socio-demographic questions, they were informed about the rules of the game, the effect of their choices on the other players' payoff, the matching mechanism and the payment system. They were then presented with the dictator games and asked a series of question to check their understanding of the game. ${ }^{10}$ After complet-

\footnotetext{
${ }^{9}$ See http://www.e-res.it and http://www.iares.it, respectively, for details.

${ }^{10}$ See the Appendix for a translation of the part of the questionnaire containing the experimental task.
} 
ing all the games they answered the remaining questions of the survey. The post-experimental questionnaire provides not only information about the subjects' socio-demographic background but also, more specifically, about their pro-social behavior, as captured by donations to non-profit institutions and participation to voluntary activities. In addition, it also provides information about subjects' well-being, measured by life satisfaction and financial satisfaction (on a scale between 1 and 10). Each interview lasted about one hour on average.

The incentive system we implemented, similar to the one used by Fong and Luttmer (2009), consists of a two-stage version of the familiar random lottery incentive system (Cubitt et al., 1998). At the beginning of the interviews one subject was randomly selected to be the recipient and completed the questionnaire without the choice task. All the other subjects played as dictators the 8 dictator games in a random sequence. Once the interviews were completed, one of the subjects among the dictators was randomly selected, together with one of the 8 games played. The choice made by this subject in the randomly selected game determined the actual payments for the active and passive subjects. The winners were then contacted by IARES and paid the prize in cash. The entire procedure was filmed and made available to all participants upon request. In the context of our experiment, this procedure is easier to implement than the usual one-stage random lottery incentive system, while ensuring the necessary saliency. Although only two subjects were paid ex post, the potential monetary prize is substantial. Furthermore, the perceived expected value is increased by the usual tendency to overestimate low probabilities (Tversky and Kahneman, 1973; see Starmer, 2000 and Burns et al., 2010, for economics and psychology-oriented reviews). Overall, the pattern of choices and their within-subject consistency confirm the salience of the incentive system.

The main benefits of the survey-based method are a larger number of respondents and a more representative population, relative to the customary pool of students, in particular with respect to age, education and income. The average age in the sample is 48 years old, with a standard deviation of 17.0 and a range between 18 and 87 , with $47.1 \%$ of males. The sample is also heterogeneous from a socioeconomic perspective, with $40.1 \%$ of respondents having a middle school education or less, $39.6 \%$ a high school education and $19 \%$ a university degree. ${ }^{11}$ The sample displays substantial variance of household income: $36.8 \%$ of respondents reported a personal income of less than 16,000 euros, $24.9 \%$ between 16,000 and 32,000 euros and $7.7 \%$ above 32,000 euros.

\footnotetext{
${ }^{11}$ The remaining $1.3 \%$ of the sample did not answer the question on educational background.
} 


\section{Results}

\subsection{Why Giving?}

Figure 2 displays the fraction of subjects who decide to give in each of the four treatments, when the size of the gift is small (100 euro). In T1, where giving is costless and reduces inequality, $17 \%$ of the subjects decide not to give, consistently with competitive preferences, while $83 \%$ of the subjects decide to give. This fraction is significantly higher than 0.5 using a binomial test with 611 independent observations ( $\mathrm{p}$-value $=0.00$ ).

Result 1: The null hypothesis of purely self-interested agents can be strongly rejected against the alternative of other-regarding preferences.

Figure 2: Giving choices, by treatment (small gift size)

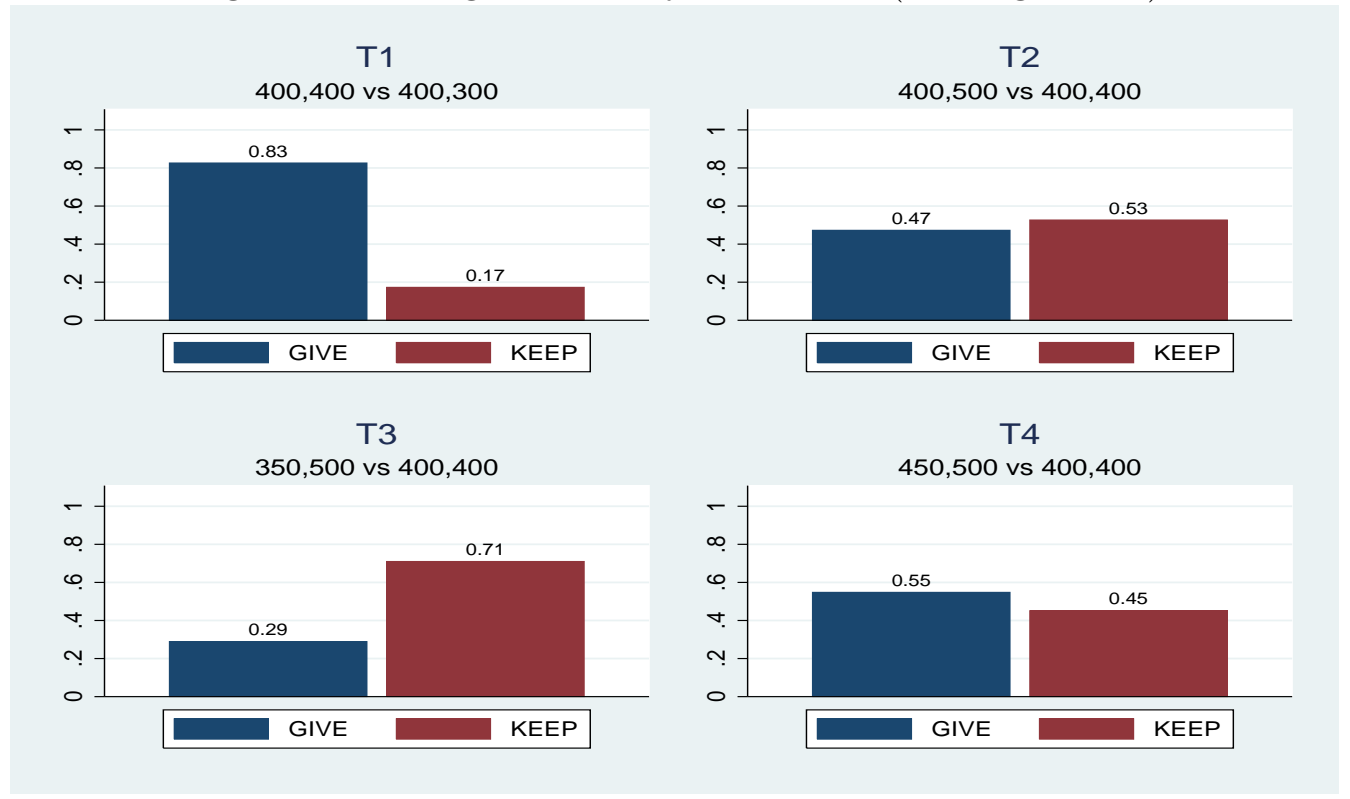

The next question we address is the relative importance of efficiency vs equality. In T2, where giving is costless and inequality-increasing, $47 \%$ of the subjects choose to give. That is, the majority of subjects prefer equal payoffs to a socially efficient but unequal allocation. The null hypothesis that $T_{2}=0.5$ cannot be rejected using a binomial test $(\mathrm{p}$-value $=0.19$, two-sided alternative).

Turning to the comparison of the percentage of subjects who give in treatments $\mathrm{T} 2$ and $\mathrm{T} 1$, the difference is strongly statistically significant (pvalue $=0.00$ for a test of proportions with a two-sided alternative). This 
indicates that differences in relative payoffs have a large and significant effect $(\delta>0)$.

Result 2: Differences in relative payoffs have a significant effect on the decision to give.

In T3, where giving is costly and inequality-increasing, the fraction of subjects who decide not to give rises to $71 \%$. The difference with respect to T2 is strongly statistically significant $(p$-value $=0.00)$, indicating that the cost of giving matters for the decision to give. In T4, where giving increases inequality and is advantageous, the fraction of subjects who decide to give is $55 \%$. Relative to T2 $(0.47 \%)$, the change is statistically significant (pvalue $=0.01)$.

Result 3: The cost of giving has a significant negative effect on the decision to give.

It should be noted that a relatively large fraction of subjects $(29 \%)$ decide to give in T3, despite the cost and the increase in inequality. Interestingly, relative to $\mathrm{T} 2$, the positive change in own payoff in $\mathrm{T} 4$ has a much smaller effect on giving than the corresponding negative change in T3. Indeed, a large fraction of subjects (45\%) decide not to give in T4, even if this is costly and socially inefficient, so that their choice can only be driven by inequity aversion.

Figure 3 displays the fraction of subjects who decide to give in each of the four treatments when the size of the gift is large (400 euro). In T1L, the fraction of subjects who give rises to $89 \%$, and the change relative to $\mathrm{T} 1$ is strongly statistically significant $(\mathrm{p}$-value $=0.00) .{ }^{12}$ In T2L, $57 \%$ of subjects decide not to give, and the increase relative to $\mathrm{T} 2$ is marginally statistically significant ( $\mathrm{p}$-value $=0.05$ for the corresponding one-sided hypothesis). This suggests that social preferences may be non-linear in relative payoffs.

Result 4: The relative weight of equity in social preferences is positively related to the size of inequality.

In T3L, the fraction of agents who give is $28 \%$, virtually unchanged relative to T3. Interestingly, T4L indicates that the size of the gift matters for positional concerns. The percentage of subjects who decide not to give rises from $45 \%$ in T4 to $50 \%$ T4L. That is, half of the subjects prefer to produce a cost both for themselves and for the other subject in order to reduce disadvantageous inequality.

\footnotetext{
${ }^{12}$ These figures are strikingly similar to the ones obtained by Charness and Grosskopf (2001) for an analogous treatment with a similar gift size.
} 
Figure 3: Giving choices, by treatment (large gift size)

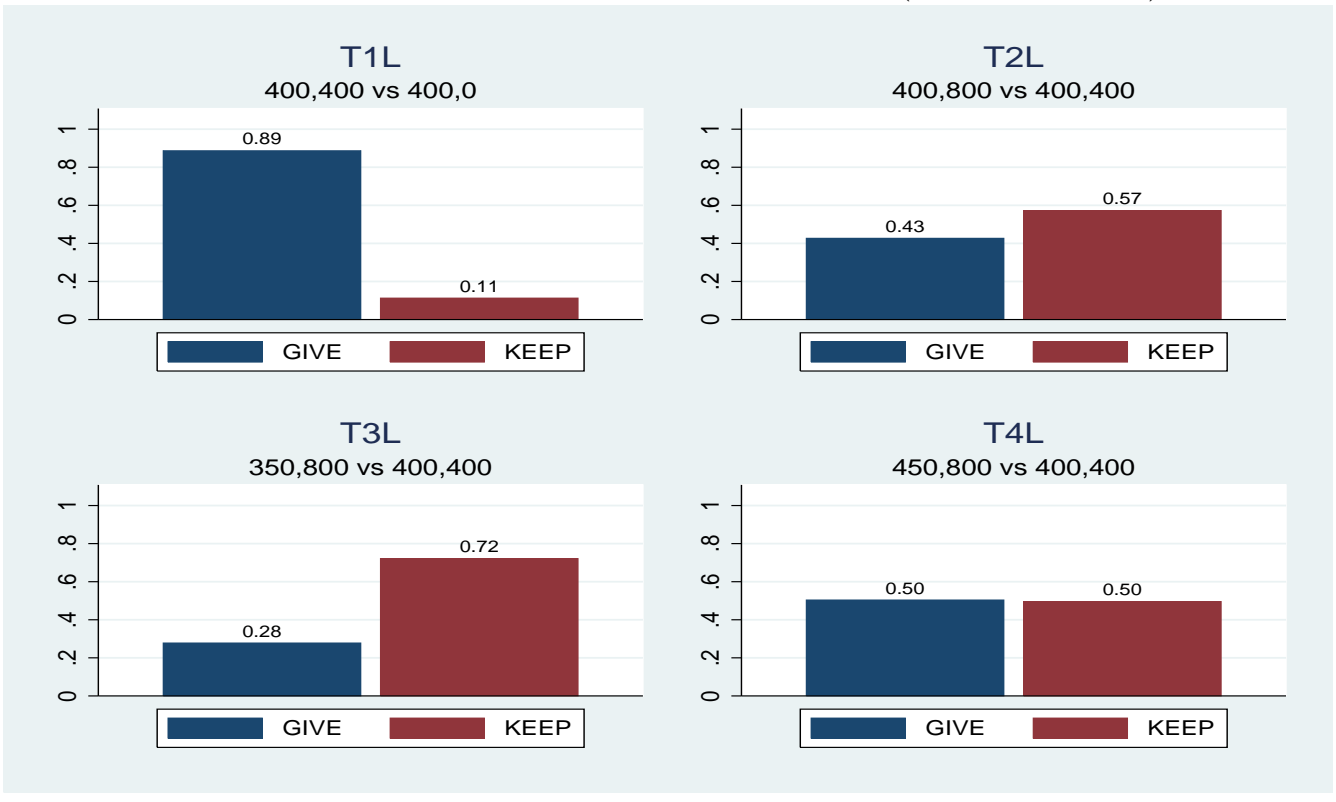

\subsection{Revealed Preferences, Reported Behavior and Out- comes}

The choices made in the experimental treatments allow us to identify different subject types. Table 2 reports summary statistics for subjects' revealed preference types and selected self-reported characteristics.

Subjects who decide not to give in both T1 and T1L can be classified as having competitive preferences. Subjects who decide to give in both treatments $\mathrm{T} 2$ and $\mathrm{T} 2 \mathrm{~L}$ can be identified as weak altruist $(\beta>\delta)$ : when giving is not costly, they are willing to accept higher inequality in order to increase $B$ 's payoff. Conversely, subjects who decide not to give in both T2 and T2L can be identified as weak positional. Subjects who decide to give in both treatments T3 and T3L are classified as strong altruist (17.5 per cent): in order to increase $\pi_{B}$ and total payoff, they are willing to accept a lower payoff and higher inequality. ${ }^{13}$ Similarly, subjects who decide not to give in both T4 and T4L are classified as strong positional: in order to avoid a lower payoff than the other subject, they are willing to accept a lower payoff both for themselves and for the other subject. ${ }^{14}$ Subjects who decide to give in

\footnotetext{
${ }^{13}$ Since $M R S=\frac{\alpha-\delta}{\beta-\delta}$, the calibration of payoffs in T3 implies that strong altruism is equivalent to $\beta>\frac{3 \delta+\alpha}{2}$.

${ }^{14}$ Given the calibration of payoffs in T4, an agent is strongly positional when $\delta>\alpha+2 \beta$.
} 
Table 2: Descriptive statistics

\begin{tabular}{lccccc}
\hline \hline \multicolumn{1}{c}{ Variable } & Mean & Std. Dev. & Min. & Max. & N \\
\hline Weak Altruist & 0.35 & 0.48 & 0 & 1 & 611 \\
Weak Positional & 0.45 & 0.5 & 0 & 1 & 611 \\
Strong Altruist & 0.18 & 0.38 & 0 & 1 & 611 \\
Strong Positional & 0.36 & 0.48 & 0 & 1 & 611 \\
Competitive & 0.05 & 0.22 & 0 & 1 & 611 \\
Life Satisfaction & 7.60 & 1.55 & 1 & 10 & 603 \\
Financial satisfaction & 6.31 & 1.93 & 1 & 10 & 603 \\
Donations (dummy) & 0.71 & 0.45 & 0 & 1 & 611 \\
Voluntary activities (dummy) & 0.62 & 0.49 & 0 & 1 & 611 \\
Male dummy & 0.47 & 0.5 & 0 & 1 & 611 \\
Age $<=25$ & 0.09 & 0.29 & 0 & 1 & 611 \\
25 $<=$ Age $<35$ & 0.17 & 0.37 & 0 & 1 & 611 \\
35 $<=$ Age $<45$ & 0.19 & 0.39 & 0 & 1 & 611 \\
35 $<=$ Age $<45$ & 0.19 & 0.39 & 0 & 1 & 611 \\
45 $<=$ Age $<55$ & 0.18 & 0.39 & 0 & 1 & 611 \\
55 $<=$ Age $<65$ & 0.15 & 0.35 & 0 & 1 & 611 \\
Age $>=65$ & 0.22 & 0.42 & 0 & 1 & 611 \\
\hline Notes: See Section 3 for a description of the variables. & & & &
\end{tabular}

T3 and T3L and not to give in T4 and T4L are classified as neither strong altruistic nor strong positional. In order to provide a description of revealed preferences, Table 3 reports pair-wise correlations between preference types identified on the basis of the choices in the experimental task.

Next, we use subjects' preferences, as revealed by their choices in the experiment, to assess their consistency with pro-social behavior, such as donations to charities and participation to voluntary organizations, as reported in the post-experimental questionnaire. The hypotheses we test are that (1) subjects with altruistic preferences are more likely to engage in pro-social activities, and (2) subjects with positional preferences are less likely to engage in pro-social activities. We use probit estimation to characterize the relationship between (both weak and strong) altruistic or positional preferences and pro-social activities at individual level. The estimated specifications also include gender, age-group and provincial dummy variables.

Table 4 reports the results for the decision to donate to charities. based on 611 independent observations. The signs of the estimated coefficients are consistent with the hypotheses: a concern for efficiency is positively related to the probability of making donations to charities, while positional preferences are negatively related to donations. The latter negative relationship is 
Table 3: Revealed Preferences: pair-wise correlations

\begin{tabular}{ccccc}
\hline \hline Variables & Competitive & Weak Altruist & Weak Positional & Strong Altruist \\
\hline Weak Altruist & 0.03 & & & \\
& $(0.48)$ & & & \\
Weak Positional & -0.05 & -0.66 & & \\
& $(0.22)$ & $(0.00)$ & & \\
Strong Altruist & 0.01 & 0.46 & -0.34 & \\
& $(0.85)$ & $(0.00)$ & $(0.00)$ & \\
Strong Positional & -0.04 & -0.51 & 0.62 & -0.34 \\
& $(0.35)$ & $(0.00)$ & $(0.00)$ & $(0.00)$ \\
\hline \hline
\end{tabular}

Notes: Pairwise-correlations based on 611 independent observations, p-values reported in brackets.

statistically significant, for both weakly and strongly positional preferences.

Table 4: Preferences and donations to non-profit organization

\begin{tabular}{lccccc}
\hline \hline & $(1)$ & $(2)$ & $(3)$ & $(4)$ & $(5)$ \\
\hline Competitive & -0.15 & & & & \\
& $(-0.62)$ & & & & \\
Weak Altruist & & 0.18 & & & \\
Weak Positional & & $(1.54)$ & & & \\
& & & $-0.24^{*}$ & & \\
Strong Altruist & & & $(-2.10)$ & 0.12 & \\
& & & & $(0.80)$ & \\
Strong Positional & & & & & $-0.24^{*}$ \\
& & & & & $(-2.11)$ \\
\hline
\end{tabular}

Notes: Dependent variable: binary variable for donations $(1=$ made donations to non-profit organizations). Probit estimates based on 611 individual observations, z-statistics reported in brackets, heteroskedasticity-robust standard errors. The set of regressors also includes gender, age-group and provincial dummy variables. ${ }^{*} \mathrm{p}<0.05,{ }^{*} *$ $\mathrm{p}<0.01$, for the relevant one-sided hypothesis.

Table 5 reports estimation results for the decision to actively participate in voluntary activities. The signs of the estimated coefficients are consistent with the hypotheses: the concern for efficiency is positively related to the probability of participating in voluntary activities, while positional preferences have instead a negative effect. The relationship is statistically significant in the case of strongly altruistic and positional preferences. Overall, these results indicate that self-reported pro-social behavior is consistent with social preferences, as revealed by the choices in the experimental treatments. 
Table 5: Preferences and participation to voluntary activities

\begin{tabular}{|c|c|c|c|c|c|}
\hline & (1) & (2) & (3) & (4) & (5) \\
\hline Competitive & $\begin{array}{l}-0.67^{*} \\
(-2.13)\end{array}$ & & & & \\
\hline Weak Altruist & & $\begin{array}{c}0.06 \\
(0.50)\end{array}$ & & & \\
\hline Weak Positional & & & $\begin{array}{c}-0.16 \\
(-1.42)\end{array}$ & & \\
\hline Strong Altruist & & & & $\begin{array}{l}0.28^{*} \\
(1.92)\end{array}$ & \\
\hline Strong Positional & & & & & $\begin{array}{l}-0.26^{*} \\
(-2.18)\end{array}$ \\
\hline
\end{tabular}

Finally, we examine the relationship between subjects' revealed preferences and their well-being. More specifically, we test the hypotheses that (1) subjects with altruistic preferences have, on average, higher levels of wellbeing, and (2) subjects with positional preferences have, on average, lower levels of well-being. We report OLS estimation results, as the results are qualitatively unchanged using ordered probit. As above, the specifications also include gender, age-group and provincial dummy variables. Table 6 reports the results, based on 603 independent observations. We do not find any significant relation between subjects' preferences and life satisfaction.

Interestingly, however, as reported in Table 7, financial satisfaction is positively related to altruistic preferences, and negatively related to positional preferences, and the latter relationship is statistically significant for weakly positional preferences. Consistently with our hypothesis, subjects who are willing to accept to be worse off in absolute terms in order to avoid being worse off in relative terms are, on average, less satisfied with their objective conditions. This result is robust to the inclusion of additional - non strictly exogenous - control variables, such as income, education, and occupation. 
Table 6: Preferences and Life Satisfaction

\begin{tabular}{|c|c|c|c|c|c|}
\hline & $\overline{(1)}$ & $\overline{~(2)}$ & (3) & $(4)$ & $\overline{(5)}$ \\
\hline Competitive & $\begin{array}{c}-0.43 \\
(-1.30)\end{array}$ & & & & \\
\hline Weak Altruist & & $\begin{array}{c}-0.02 \\
(-0.16)\end{array}$ & & & \\
\hline Weak Positional & & & $\begin{array}{l}-0.16 \\
(-1.24)\end{array}$ & & \\
\hline Strong Altruist & & & & $\begin{array}{c}0.05 \\
(0.32)\end{array}$ & \\
\hline Strong Positional & & & & & $\begin{array}{c}-0.07 \\
(-0.52)\end{array}$ \\
\hline
\end{tabular}

Note: Dependent variable: Life satisfaction. OLS estimates based on 603 individual observations. z-statistics reported in brackets, heteroskedasticity-robust standard errors. The set of regressors also includes gender, age-group and provincial dummy variables. ${ }^{*}$ $\mathrm{p}<0.05,{ }^{* *} \mathrm{p}<0.01$.

Table 7: Preferences and Financial Satisfaction

\begin{tabular}{|c|c|c|c|c|c|}
\hline & (1) & $(2)$ & $(3)$ & (4) & $(5)$ \\
\hline Competitive & $\begin{array}{c}-0.34 \\
(-1.16)\end{array}$ & & & & \\
\hline Weak Altruist & & $\begin{array}{c}0.10 \\
(0.61)\end{array}$ & & & \\
\hline Weak Positional & & & $\begin{array}{c}-0.37^{* *} \\
(-2.35)\end{array}$ & & \\
\hline Strong Altruist & & & & $\begin{array}{c}0.17 \\
(0.84)\end{array}$ & \\
\hline Strong Positional & & & & & $\begin{array}{c}-0.15 \\
(-0.95)\end{array}$ \\
\hline
\end{tabular}




\section{Conclusions}

This paper presented a survey-based experimental analysis of the respective roles of equity and efficiency for altruistic behavior. Our results indicate that both efficiency and equity matter for the decision to give. Inequality aversion, however, is found to play a major role. When giving is not costly, differences in relative payoffs have a significant effect on the decision to give, and the majority of subjects prefer equal payoffs to social efficiency. When giving is payoff-increasing, half the subjects choose to sacrifice in order to decrease inequality through pareto-damaging behavior.

Our results, based on a representative pool of subjects with large monetary incentives, are at odds with several existing laboratory experiments using students as subjects. These studies generally conclude that inequality reduction plays a relatively minor role for the decision to give, while emphasizing the role of social efficiency (Charness and Rabin, 2000, Charness and Grosskopf, 2001, Engelmann and Strobel, 2004, Zizzo and Oswald, 2001). We conclude, instead, that the role of efficiency for the decision to give may have been exaggerated. When the sample of subjects is representative, and the stakes are large, the decision to give is to a large extent determined by relative payoffs.

We also exploited the post-experimental questionnaire to investigate the relationship between revealed preferences and reported behavior. We found that preferences, as revealed by experimental choices, are largely consistent with reported pro-social activities: on the one hand, a concern for efficiency in the experimental task is positively related to the probability of participating in voluntary activities; on the other hand, inequity aversion negatively affects the probability of both making donations to charities and participating in voluntary activities.

Finally, we examined the relationship between revealed pro-social preferences and self-reported well-being. Similarly to Charness and Grosskopf (2001), we do not find any significant relation between subjects' revealed preferences and life satisfaction. On the other hand, financial satisfaction is negatively affected by positional preferences: subjects with positional preferences, who are willing to accept to be worse off in absolute terms in order to avoid being worse off in relative terms, are significantly less satisfied, ceteris paribus, with their financial conditions.

Overall these results, based on a large and representative sample of subjects with substantial monetary incentives, contribute to our understanding of social preferences in the real world. They also help us to assess the implications of other-regarding preferences for individual behavior and outcomes. 


\section{Appendix: Instructions}

By answering this section of the questionnaire, you can win a substantial prize in euro. You have to answer a series of 8 questions. If your name will be extracted among those who participate in this survey, one of the 8 answers you provide will be randomly selected to determine the corresponding prize. Note that you will be matched to another randomly selected participant, who will also win a prize that will depend on your choices.

Example:

Which would you choose between the following two options?

A) you win 200 euros and the other subject wins 200 euros

B) you win 300 euros and the other subject wins 250 euros

By choosing A, you would win 200 euro and the other subject would win 200 euro. By choosing B, you would win 300 euro and the other subject would win 250 euro.

Let us now turn to the actual questions, that might determine your actual win [The order of the 8 choices was randomized]

1. Your choice:

(a) you win 400 euros and the other subject wins 400 euros

(b) you win 400 euros and the other subject wins 300 euros

2. Your choice:

(a) you win 400 euros and the other subject wins 400 euros

(b) you win 400 euros and the other subject wins 500 euros

3. Your choice:

(a) you win 400 euros and the other subject wins 400 euros

(b) you win 350 euros and the other subject wins 500 euros

4. Your choice: 
(a) you win 400 euros and the other subject wins 400 euros

(b) you win 450 euros and the other subject wins 500 euros

5. Your choice:

(a) you win 400 euros and the other subject wins 400 euros

(b) you win 400 euros and the other subject wins 000 euros

6. Your choice:

(a) you win 400 euros and the other subject wins 400 euros

(b) you win 400 euros and the other subject wins 800 euros

7. Your choice:

(a) you win 400 euros and the other subject wins 400 euros

(b) you win 350 euros and the other subject wins 800 euros

8. Your choice:

(a) you win 400 euros and the other subject wins 400 euros

(b) you win 450 euros and the other subject wins 800 euros 


\section{References}

Andreoni, J., 2006. Philanthropy, In Handbook of Giving, Reciprocity and Altruism, S-C. Kolm and J. Mercier Ythier, eds. Amsterdam: North Holland, pp. 1201-69.

Bellemare, C., Kroger, S., 2007. On Representative Social Capital. European Economic Review, 51, 183-202.

Bellemare, C., Kroger, S., Van Soeste A., 2008. Measuring Inequity Aversion in a Heterogeneous Population Using Experimental Decisions and Subjective Probabilities. Econometrica 76(4), 815-839.

Bolton, G.E., Ockenfels, A., 2000. ERC - A Theory of Equity, Reciprocity and Competition. American Economic Review 90, 166-193.

Brown, E., 2005. College, social capital, and charitable giving. In A. C. Brooks (Ed.), Gifts of time and money: The role of charity in america's communities. Rowman \& Littlefield.

Burns, Z., Chiu, A., Wu, G., 2010. Overweighting of Small Probabilities. Mimeo, forthcoming in the Wiley Encyclopedia of Operations Research and Management Science

Charness, G., Grosskopf, B., (2001). Relative Payoffs and Happiness: An Experimental Study. Journal of Economic Behavior and Organization, $45,301-328$.

Charness, G., Rabin, M., 2002. Understanding Social Preferences with Simple Tests. Quarterly Journal of Economics, 117, 817-869.

Cubitt, R., Starmer, C., Sugden, R., 1998. On the Validity of the Random Lottery Incentive System. Experimental Economics 1, 115-131.

Dufwenberg M., Kirchsteiger, G., 2004. A Theory of Sequential Reciprocity. Games and Economic Behavior 47, 268-298.

Engelmann, D., Strobel, M., 2004. Inequality Aversion, Efficiency, and Maximin Preferences in Simple Distribution Experiments. American Economic Review 94, 857-869.

Falk, A., Fehr, E., Fischbacher, U., 2008. Testing Theories of Fairness Intentions Matter. Games and Economic Behavior 62, 287-303.

Falk, A., Fehr, E., Fischbacher, U., 2003. On the Nature of Fair Behaviour. Economic Inquiry 41, 20-26. 
Falk, A., Fischbacher, U., 2006. A Theory of Reciprocity. Games and Economic Behavior 54, 293-315.

Fehr, E., Fischbacher, U., von Rosenbladt, B., Schupp, J., Wagner, G., 2003. A Nation?Wide Laboratory: Examining Trust and Trustworthiness by Integrating Behavioral Experiments into Representative Surveys. IZA Discussion Papers 715, Institute for the Study of Labor.

Fehr, E., Gächter, S., 2000. Fairness and Retaliation: The Economics of Reciprocity. Journal of Economic Perspectives 14, 159-181.

Fehr, E., Schmidt, K.M., 1999. A Theory of Fairness, Competition, and Cooperation, Quarterly Journal of Economics 114, 817-868.

Fehr, E., Schmidt, K.M., 2006. The Economics of Fairness, Reciprocity and Altruism: Experimental Evidence. In: Kolm, S.C., Ythier, J.M. (Eds). Handbook of the Economics of Giving, Altruism and Reciprocity 1, 615-691.

Fong C., Luttmer, E. 2009. Do Race and Fairness Matter in Generosity? Evidence from a Nationally Representive Charity Experiment. NBER Working Paper n. 15064.

Giving USA, 2010. Report 2010, Center on Philantropy at Indiana University, http://www.givingusareports.org/free.php

Glaeser E., Laibson, D.I., Scheinkman, J.A., Soutter, C.L., 2000. Measuring trust, Quarterly Journal of Economics 115, 811-846.

Gachter, S., Falk, A., 2002. Reputation and Reciprocity: Consequences for the Labour Relation. Scandinavian Journal of Economics 104, 1-26.

Havens, J. J., O’Herlihy, M. A., Scervish, P. G., 2006. Charitable giving: How much, by whom, to what, and how? In W. W. Powell \& R. Steinberg (Eds.), The non-profit sector: A research handbook. New Haven/London: Yale University, 542-567 Press.

McCabe, K.A., Rigdon, M.L., Smith, V.L., 2003. Positive Reciprocity and Intentions in Trust Games. Journal of Economic Behavior and Organization 52, 267-275.

Nelson, W., 2002. Equity or Intention: It Is the Thought That Counts. Journal of Economic Behavior and Organization, 48(4), 423-30. 
Rabin, M.,1993. Incorporating Fairness into Game Theory and Economics. American Economic Review 83, 1281-1302.

Rooney, P. M., Mesch, D. J., Chin, W., Steinberg, K. S., 2005. The effects of race, gender and survey methodologies on giving in the us. Economics Letters, 86, 173-180.

Sapienza, P., Toldra, A., Zingales, L., 2008. Understanding Trust, NBER Working Papers 13387, National Bureau of Economic Research.

Sobel J., 2005. Interdependent Preferences and Reciprocity. Journal of Economic Literature 43, 392-436.

Starmer, C., 2000. Developments in Non-Expected Utility Theory: The Hunt for a Descriptive Theory of Choice under Risk. Journal of Economic Literature 38, 332-382.

Sutter, M., 2007. Outcomes versus Intentions: On the Nature of Fair Behavior and Its Development with Age. Journal of Economic Psychology, vol. 28, no. 1, January 2007, 69-78.

Tversky, A., Kahneman, D., 1973. Availability - Heuristic for Judging Frequency and Probability. Cognitive Psychology 5, 207-232.

Zizzo and Oswald, (2001) Are People Willing to Pay to Reduce Others' Incomes 